\title{
A contextualização e seus impactos nos processos de ensino e aprendizagem da ciência química
}

Isadora Finger*, Everton Bedin**

\section{Resumo}

A prática de contextualizar no ensino de química, apesar de ser dificilmente encontrada, é uma atividade significativa para a construção da aprendizagem do aluno, pois, quando realizada de forma satisfatória, tem a capacidade de significar seus conhecimentos do contexto à luz da maximização e aquisição do conteúdo científico. Nesse sentido, o presente artigo tem o objetivo de entender de que forma a contextualização é utilizada no ensino de química e como ela pode impactar na postura e no aprendizado dos estudantes à luz da participação em sala de aula, bem como na conexão entre os saberes e os conteúdos científicos. Os dados foram coletados por meio da observação em quatro aulas diferentes no ensino técnico, considerando-se o uso do diário de bordo e a interpretação e a reflexão da escrita neste para a qualificação dos dados. No término, pode-se perceber que a contextualização qualifica o processo de ensinagem, na medida em que o aluno faz parte cooperativa da construção do seu saber científico a partir do seu contexto, além de que esta é uma forma de demonstrar as competências e habilidades do docente, proliferando saberes e reflexões acerca de sua formação inicial e a necessidade de uma formação continuada com vistas a metodologias de ensino que valorizam o saber do aluno.

Palavras-chave: Contextualização. Ensino de química. Saberes.

* Técnica em Química pela Fundação Escola Técnica Liberato Salzano Vieira da Cunha. Graduanda em Química Licenciatura na Universidade Luterana do Brasil (Ulbra). E-mail: fingerisa@gmail.com

* Doutor e pós-doutorando em Educação em Ciências: Química da Vida e Saúde na Universidade Federal do Rio Grande do Sul (Ufrgs). Professor no Programa de Pós-Graduação em Ensino de Ciências e Matemática da Ulbra. E-mail: everton.bedin@ulbra.br 


\section{Introdução}

Não é novidade que o ensino de química na educação básica vem enfrentando dificuldades no que diz respeito à compreensão e à significação dos saberes científicos pelos alunos durante as aulas. Estes problemas, muitas vezes, estão relacionados a não eficácia das ações e práticas docentes nos processos de ensino e aprendizagem, sendo visíveis por meio do não relacionamento entre o saber do aluno/contextual e o saber científico. Muitas vezes, é difícil para os professores conseguirem despertar o interesse dos alunos, de modo a instigar a atenção, pois os alunos apresentam uma espécie de "bloqueio" quando o assunto envolve conteúdo de ciências exatas e, principalmente, de química, já que este ensino, em sua grande maioria, é desenvolvido de forma expositiva e demonstrativa.

Assim, de um lado, há docentes com grandes desafios, tais como buscar uma formação continuada enraizada em saberes didáticos e profissionais e desenvolver formas de instigar os estudantes para trazê-los ao universo da ciência; do outro, há alunos com dificuldades em aprender e se interessar por este mundo. Contudo, há de se entender que este processo ocorre por diversos fatores, sendo um dos principais o fato de que o estudante não consegue ver fundamento e aplicabilidade no que aprende durante as aulas de química, não sendo capaz de relacioná-las com o seu cotidiano ou com aquilo que o rodeia. Assim, as aulas perdem o significado e se tornam árduas tanto para o aluno quanto para o professor, o qual que tem a missão de fomentar os educandos e açodá-los à aprendizagem.

Tendo-se por base a situação supracitada, o presente trabalho, a partir da observação, tem por objetivo entender de que forma a contextualização é utilizada no ensino de química e como ela pode impactar na postura e no aprendizado dos estudantes à luz da participação em sala de aula, bem como na conexão entre os saberes e os conteúdos científicos. Logo, tem-se a concepção de que a utilização da contextualização durante as aulas de química pode, além de instigar a participação do aluno para a abrangência de seus saberes e a conexão com a sua vivência, intensificar e maximizar os processos de ensino e aprendizagem de forma satisfatória na educação básica.

Este artigo se justifica na medida em que se considera, como ponto de partida de uma escola que apresenta baixa infraestrutura e mínimos recursos para a utilização de materiais didáticos diferenciados do quadro e giz, que a contextualização é um 
processo que o professor desenvolve e aprimora em conjunto com o aluno; o momento de contextualizar ocorre em uma via dupla; há trocas de saberes e conhecimentos entre professor e aluno, tornando este último um ser ativo no próprio processo de construção de conhecimentos à luz de sua vivência.

\section{Aportes teóricos}

O ensino de química, certamente, é um dos que mais enfrenta dificuldades no sentido da efetividade e qualificação dos processos de ensino e aprendizagem na educação básica, tanto do ponto de vista do professor, incumbido de facilitar o processo de ensino, quanto para os alunos, que necessitam construir, absorver e obter um real entendimento sobre o que lhes é facilitado na aprendizagem. Esse "obstáculo" - existente não só no ensino de química, mas no ensino de ciências em geral - pode estar relacionado com o fato de que, nessas disciplinas, são trabalhados conteúdos considerados muito difíceis pela maioria dos alunos e que, em sua maior parte, são feitos de forma expositiva e sem contextualização.

Essa dificuldade, por sua vez, muito provavelmente tem sua origem na incapacidade dos alunos de relacionar o conteúdo de química com a sua vivência e na formação docente, que se detém apenas ao conteúdo e não à profissionalização - não havendo competências para relacionar o contexto do aluno ao conteúdo a ser transmitido. De forma semelhante, tanto aluno quanto professor apresentam dificuldades para encontrar aplicação e utilidade para aquilo que está em pauta em sala de aula. No entanto, é válido ressaltar que é, principalmente, papel do docente ser capaz de fazer essa conexão e transmiti-la aos alunos, mesmo estes apresentando saberes satisfatórios em relação ao conteúdo e ao seu contexto.

Segundo Santos (2013, p. 1), “[...] comumente, observamos que alunos e professores não compreendem os verdadeiros motivos para estudar e ensinar Química, e ainda, parte da motivação para estar relacionada com a futura profissão a ser seguida”. Este é um problema enfrentado nas escolas e que, sem dúvidas, potencializa os obstáculos existentes nos processos de ensino e aprendizagem desta ciência.

Afinal, conforme Santos (2013, p. 2): 
Pesquisas têm mostrado que o ensino de Química geralmente vem sendo estruturado em torno de atividades que levam a memorização de informações, fórmulas e conhecimentos que limitam o aprendizado dos alunos e contribuem para a desmotivação em aprender Química [...]. As pesquisas mostram, ainda, que os alunos do ensino médio, geralmente apresentam baixos níveis de aprendizagens em avaliações internas realizadas no contexto da própria escola por professores, e nas externas realizadas por programas de avaliações mantidos pelo Ministério da Educação (MEC).

Tendo isso em vista, é de imensurável importância que o docente admita com seriedade o compromisso de instigar o aluno em sala de aula, despertando a sua curiosidade e o seu interesse por meio da contextualização dos saberes científicos a partir da sua realidade de vida. As atividades sistemáticas de memorização e repetição não são as melhores formas de fazer isso, visto que grande parte dos alunos não apresenta um aprendizado satisfatório com esse método; tão pouco, pedagogicamente, ele é indicado na construção de saberes de forma autônoma e reflexiva.

Uma boa alternativa para isso pode ser a utilização da contextualização no ensino de química, afinal, de acordo com Oliveira (2005, p. 13), a contextualização deve ser entendida como um recurso para "[...] promover inter-relações entre conhecimentos escolares e fatos/situações presentes no dia-a-dia dos alunos, contextualizar é imprimir significados aos conteúdos escolares, fazendo com que os alunos aprendam de forma significativa".

Essa "aprendizagem significativa" é valorosa e pode ser entendida como aquela em que o aluno realmente vê sentido no que aprende; ao se tornar autor da própria formação, percebendo os saberes científicos em seu dia a dia, o aluno sente-se motivado a aprender e a fazer parte deste processo. Para o desenvolvedor da abordagem centrada na pessoa, o psicólogo Carl Rogers (2001, p. 323), a aprendizagem significativa é:

[...] uma aprendizagem que é mais do que uma acumulação de fatos. É uma aprendizagem que provoca uma modificação, quer seja no comportamento do indivíduo, na orientação futura que escolhe ou nas suas atitudes e personalidade. É uma aprendizagem penetrante, que não se limita a um aumento de conhecimentos, mas que penetra profundamente todas as parcelas da sua existência.

Dessa forma, para promover eficazmente uma aprendizagem significativa, a contextualização vem como um mecanismo facilitador, sendo notório que, quando o aluno consegue conectar determinado conceito teórico com sua prática cotidiana, o seu entendimento se torna real e verdadeiro. Em contrapartida, se não encontrar 
uma aplicabilidade daquilo que está buscando aprender, quando os conceitos estão muito longe da realidade, o aprendizado se torna demasiadamente ímprobo. Por isso, é importante que o professor envolva o aluno, contextualize o conteúdo a ser discutido, problematizando-o junto com a turma, uma vez que "[...] na problematização deve-se apresentar aos alunos situações reais, conhecidas e vivenciadas por eles, envolvidas nos temas. A meta é problematizar o conhecimento que os alunos expõem" (SILVA, 2010, p. 105).

Nesta perspectiva, os Parâmetros Curriculares Nacionais para o Ensino Médio também sugerem a contextualização como sendo um recurso fundamental no ensino, do qual deve ser tirado proveito para a melhoria da educação.

O tratamento contextualizado do conhecimento é o recurso que a escola tem para retirar o aluno da condição de espectador passivo. Se bem trabalhado permite que, ao longo da transposição didática, o conteúdo do ensino provoque aprendizagens significativas que mobilizem o aluno e estabeleçam entre ele e o objeto do conhecimento uma relação de reciprocidade. A contextualização evoca por isso áreas, âmbitos ou dimensões presentes na vida pessoal, social e cultural, e mobiliza competências cognitivas já adquiridas (BRASIL, 2000, p. 78).

Assim, fica evidente o quão crucial é fazer uso da contextualização na prática docente, em especial no ensino de química, não por se tratar de uma ciência específica em fórmulas, códigos e números, mas por ser essencial para a qualidade de vida e a manutenção consciente do meio ambiente, pois, além de despertar habilidades cognitivas e motoras, a contextualização, quando realizada com eficiência, é capaz de mobilizar competências e saberes nos alunos.

Corroborando, as Orientações Curriculares para o Ensino Médio (BRASIL, 2006, p. 117) sugerem a contextualização de temas socialmente relevantes para o ensino de química, quando defendem a ideia de:

[...] uma abordagem de temas sociais (do cotidiano) e uma experimentação que, não dissociados da teoria, não sejam pretensos ou meros elementos de motivação ou de ilustração, mas efetivas possibilidades de contextualização dos conhecimentos químicos, tornando-os socialmente mais relevantes [...].

Portanto, contextualizar no ensino de química é uma forma de qualificar e aprimorar a aprendizagem, para que os alunos consigam relacionar os saberes da sociedade com os conteúdos científicos, a fim de que, para além de perceberem-nos em suas roupas, comidas e produtos do cotidiano em geral, consigam despertar 
interesse próprio pelo assunto para usufruir desses saberes e, de forma positiva, intervir no meio social em que se situam.

\section{Desenho da pesquisa}

Os dados da pesquisa foram coletados a partir de observações realizadas nas aulas de química em uma escola pública de ensino médio e técnico, inclusive com o técnico em Química, situada na cidade de Novo Hamburgo, região metropolitana de Porto Alegre, capital do estado gaúcho. Como se trata de uma escola técnica, foram acompanhadas aulas de diferentes disciplinas do currículo de Química e, consequentemente, de diferentes turmas.

As aulas, sem interrupções orais ou físicas, foram apenas observadas por uma acadêmica de licenciatura em Química, como requisito para a aprovação na disciplina de Estágio Supervisionado I de um curso de graduação de uma universidade comunitária do município de Canoas, região vizinha a Novo Hamburgo. As aulas observadas na escola técnica foram das disciplinas: Polímeros, Química Orgânica I, Química Inorgânica I e Processos Industriais I (Tintas).

A partir disso, em um diário de bordo, foram anotados minuciosamente os momentos das aulas, examinando de que forma os professores faziam uso da contextualização e como esta prática impactava na participação, no comportamento e na aprendizagem dos alunos, para posteriormente ser realizada uma análise dos dados levantados à luz de discussões com teóricos da área.

O diário de bordo foi essencial para a atividade de observação, uma vez que se trata de uma ferramenta em que o observador escreve sobre o observado e, em seguida, reflete sobre a escrita. Esta, por sua vez, vem sendo evidenciada como uma importante ferramenta na formação docente por diversos autores. Para Alves (2001, p. 224), trata-se de um “[...] registro de experiências pessoais e observações passadas, em que o sujeito que escreve inclui interpretações, opiniões, sentimentos e pensamentos, sob uma forma espontânea de escrita, com a intenção usual de falar de si mesmo". Portanto, o diário de bordo, aliado à prática de observação, é um documento que apresenta um caráter descritivo e investigativo, o qual consiste em uma fonte de construção e reconstrução do conhecimento e do agir de registros quantitativos e qualitativos. 


\section{Quatro aulas e três contextualizações: a aprendizagem emerge para além da relação professor-aluno}

Durante a observação, foram acompanhadas quatro aulas. As três primeiras foram observadas em turmas noturnas, enquanto a última - Processos Industriais I (Tintas) - foi observada em uma turma diurna. Os dados foram coletados mediante anotações minuciosas dos acontecimentos no decorrer das aulas no diário de bordo, prestando-se atenção especialmente ao uso ou não uso da contextualização por parte dos professores para explicar os conteúdos bem como às atitudes dos alunos diante disto. A partir da observação e dos dados coletados, foi possível fazer um levantamento para analisar o impacto desta atividade no ensino de química.

A aula da professora 1, ministrante da matéria de Polímeros, deu-se durante 4 períodos, sendo que nesta aula havia 12 alunos em sala (muitos faltaram devido à ocorrência de fortes chuvas). Nesta aula, vale ressaltar que, desde o início, a professora mostrou ter uma postura de respeito em relação aos alunos. Por exemplo, em uma aula anterior, os alunos, em grupos, apresentaram um seminário, no qual cada grupo falou sobre determinado polímero (PVC, polipropileno, polietileno e assim por diante). Na aula em que foi feita a observação, a professora 1 iniciou-a dando as notas do seminário anterior, sendo que, ao invés de dizer os nomes e as respectivas notas, a professora optou em dizer o nome do polímero e a nota, respectivamente, evitando possíveis constrangimentos.

Na sequência, a professora deu início ao conteúdo envolvendo o processo de transformação de plásticos. Ela explicou quando e de que forma acontecem a extrusão e a injeção, sempre relacionando com o contexto do aluno e com a indústria, principalmente por se tratar de um curso técnico em Química. Para isso, ela fez uso de vídeos, mostrando como funciona cada etapa desses processos; mencionou as embalagens de shampoo e de outros produtos que são utilizados em casa, questionando e instigando os alunos sobre a forma em que ocorria o processo de obtenção daquelas embalagens.

Neste desenho, é cabível destacar a ideia de que utilizar vídeos no ensino de química é uma forma de, além de contextualizar o cotidiano e mostrar onde diferentes processos químicos estão implicitamente presentes, fazer com que o aluno se sinta atraído e curioso pelo saber. Afinal, a prática do uso do vídeo como recurso pedagógico traz a possibilidade de utilizar não somente palavras, mas também 
imagens, muitas vezes mais atrativas e persuasivas do que a fala do professor, ocasionando um impacto maior do que a utilização de um livro didático ou de uma aula expositiva (MARCELINO-JR. et al., 2004).

A professora passou para os alunos embalagens plásticas, como potes e frascos de produtos, e explicou como que, a partir da observação física delas, é possível saber qual foi o processo de produção de cada uma (se injeção, extrusão, etc.). Durante a exposição do conteúdo, os alunos se mostraram bastante participativos, fizeram questionamentos e responderam o que era problematizado pela professora. Algum tempo depois, a professora distribuiu embalagens plásticas diferentes para cada aluno e perguntou, individualmente, como estas eram produzidas. Todos os alunos acertaram o processo de fabricação de suas respectivas embalagens, evidenciando que a forma contextualizada utilizada pela professora para explicar os conceitos foi eficiente.

A aula foi bem dialogada e contextualizada, não houve perda de tempo ou reclamações para copiar o conteúdo, já que os alunos tinham um polígrafo para acompanhar o processo e participar ativamente da aula. Assim, é importante destacar que a contextualização no ensino, nas palavras de Ramos (2004, p. 2):

É um importante meio de estimular a curiosidade e fortalecer a confiança do aluno. Por outro lado, sua importância está condicionada à possibilidade de levar o aluno a ter consciência sobre seus modelos de explicação e compreensão da realidade, reconhecê-los como equivocados ou limitados a determinados contextos, enfrentar o questionamento, colocá-los em cheque num processo de desconstrução de conceitos e reconstrução/apropriação de outros.

Após explicar essa parte do conteúdo, a professora progrediu para um novo: controle de qualidade. Para desenvolver essa parte da matéria, a professora utilizou uma apresentação de slides. No entanto, novamente, ela não se prendeu a uma metodologia tradicional e buscou a interação dos alunos por meio da sondagem inicial e da contextualização. Basicamente, esta ação foi desenvolvida por meio da menção à indústria, evidenciando onde e como os alunos aplicariam aquele conhecimento na prática.

Diante dessa primeira observação e a partir dos dados coletados, é possível ajuizar que a forma de desenvolver o processo de ensinagem utilizada pela professora gerou impactos positivos nos alunos, fortalecendo o elo entre a ciência e a aprendizagem. Como se trata de uma turma noturna, muitos deles já estão inseridos no mercado de trabalho e já passaram por pelo menos um estágio na área. 
Nesse sentido, ressalva-se que, enquanto a professora explicava e contextualizava os conceitos envolvendo polímeros, bem como os seus processos de transformação e controle de qualidade, os alunos traziam questões provenientes dos seus empregos. Surgiram dúvidas, comentários e até contribuições a respeito do que estava sendo abordado, principalmente em relação aos testes de controle de qualidade, visto que alguns deles trabalharam no ramo. Esse foi o primeiro ponto positivo observado em relação ao fato de a professora utilizar a contextualização em sala de aula e ser aberta ao diálogo, suficientemente, para deixar o aluno tornar-se aprendiz dos seus saberes.

É necessário, ainda, lembrar que os alunos se mantiveram "presos" à explicação da professora. Isso pode ser evidenciado pelo fato de que eles não se dispersaram, conversaram ou utilizaram celular - práticas corriqueiras em múltiplas escolas públicas. Isso foi uma surpresa boa, já que atualmente é difícil acompanhar uma aula em que os alunos não utilizem seus smartphones. É importante destacar que, apesar de os alunos não terem conversado, eles não se mostraram apáticos, já que a turma foi extremamente participativa e mostrou real interesse no conteúdo abordado, logrando satisfação quanto aos saberes referentes aos processos de transformação dos plásticos.

A segunda aula observada foi a de Química Orgânica I, também no período noturno e com igual duração de 4 períodos. Havia 20 alunos presentes. O professor inicialmente fez a devolução de uma avaliação feita noutro momento, a fim de que os alunos vissem seus acertos e erros, podendo esclarecer dúvidas e incertezas em relação ao conteúdo. O professor passou de mesa em mesa, conforme estava sendo solicitado para resolver as questões que não haviam ficado claras. Da mesma forma que a professora de Polímeros, o professor de Química Orgânica I demonstrou ter uma relação de respeito, preocupação e proximidade com os alunos. O fato de não ter exposto a turma com suas notas foi uma evidência disso, pois muitos estudantes não gostam de compartilhar suas notas e se sentem constrangidos diante disso.

Após um bom tempo esclarecendo dúvidas, aluno por aluno, o professor deu início ao conteúdo sobre reação de combustão. Da mesma forma que a professora de Polímeros, o professor também fez uso de contextualização para explicar como funciona uma reação de combustão. Para isso, ele destacou como ela é importante para o nosso cotidiano, já que é um processo para gerar energia térmica, sendo utilizada 
para várias finalidades. Um dos exemplos utilizados pelo professor foi a combustão presente nos automóveis; ele citou como os combustíveis, a gasolina e o etanol, por exemplo, sofrem combustão e geram energia, sendo essa energia responsável pela movimentação dos veículos.

Diante disso, foi notório como os estudantes se mantiveram atentos à explicação, já que fizeram questionamentos e participaram da explicação do professor. Um dos alunos, inclusive, perguntou o que aconteceria se a combustão nos automóveis não fosse completa. O professor, munido de competências e habilidades, soube esclarecer a dúvida do aluno e, a partir disso, introduzir a parte do conteúdo envolvendo reação de combustão incompleta.

Após a explicação da parte teórica, o professor fez questões contextualizadas no quadro, a fim de mostrar os cálculos teóricos e suas aplicabilidades, bem como esclarecer possíveis dúvidas dos alunos. Na sequência, ele determinou um tempo para que os alunos pudessem realizar os exercícios e passou de classe em classe, para minimizar as dúvidas. Foi possível observar que os alunos realmente faziam os exercícios, conversavam entre si para tentar resolvê-los de forma cooperativa e, quando não conseguiam, chamavam o professor.

Para finalizar a aula, o professor mencionou o craqueamento, fazendo uma relação significativa com a indústria do petróleo. Isso se mostra extremamente relevante, visto que a contextualização, conforme Ricardo (2005, p. 78), está “[...] associada a uma aprendizagem que tenha sentido para o aluno e se recomenda 0 trabalho, a cidadania, o corpo, a saúde e o meio ambiente como contextos principais, embora maior ênfase seja dada ao trabalho".

No término desta aula, ficou evidente que os alunos construíram conhecimento durante a aula, já que conseguiram resolver os exercícios propostos pelo professor (mesmo naqueles em que apresentaram dificuldades) e dialogar sobre diferentes contextos relacionados ao conteúdo. Além disso, apenas dois alunos fizeram uso do celular no decorrer da aula, mas, enquanto o professor explicava os conceitos de forma contextualizada, participaram, questionaram e sanaram as incertezas sobre o conteúdo. Portanto, é possível compreender que o uso da contextualização, além de instigar o aluno para participar ativamente da aula e tornar-se um membro da construção do saber, favorece a organização e a constituição do conhecimento de forma cooperativa entre alunos e professor, pois contextualizar é uma forma de aprimorar os saberes do cotidiano do aluno 
por meio daquilo que ele busca em sala de aula: conhecimentos científicos relacionados à ideia macro do próprio contexto.

A terceira aula observada foi a de Química Inorgânica I, também com duração de 4 períodos e no turno da noite, sendo assistida por 16 alunos. Inicialmente, eles estavam bem agitados, conversando bastante, o que fez com que a professora chamasse a atenção deles. Após a advertência da professora, eles se mantiveram em silêncio e passaram a participar da aula.

A aula teve início com a resolução de exercícios que a turma deveria ter realizado em casa, como tarefa extraclasse. A professora deu ênfase ao fato de que corrigiria no quadro apenas aqueles exercícios que os alunos solicitassem e nos quais apresentassem dificuldades. Uma aluna solicitou que a professora explicasse no quadro a questão número 2, que se subdividia em A, B e C. Diante disso, a professora questionou o "porquê" de pedir para resolver a letra A, insinuando ser algo fácil e óbvio, complementando: "Mas tu tens cara de quem conseguiu fazer essa". Esse comportamento da professora demonstra certo julgamento em relação ao aluno, pois o fato de ela dar a entender que a questão era fácil para ser resolvida no quadro pode desestimular outros alunos que pretendiam realizar questões sobre suas dúvidas.

Após, sem mais questionamentos, a professora deu início ao conteúdo novo sobre reagente limitante e em excesso, sem introduzi-lo por meio da contextualização. Os alunos possuíam um polígrafo para acompanhar o conteúdo e a explicação, mas, ao invés disso, muitos estavam fazendo uso do celular. A professora resolveu uma questão, como forma de exemplo, de um cálculo envolvendo reagente limitante e em excesso. Nesse momento, ela perguntou para os alunos: "Qual será o resultado aqui?". Alguns alunos se mantiveram quietos e indiferentes, enquanto outros continuaram mexendo em seus smartphones.

A turma estava tão apática que a professora teve que chamar a atenção, gritando: "Reajam, pessoal!". Esse comportamento dos alunos demonstra a falta de interesse pelo que estava sendo explicado pela professora, enfatizando, ainda, que eles não foram instigados e suas curiosidades não foram despertadas, já que não percebiam aplicabilidade do conteúdo em suas vidas. Um aluno falou: "Professora, mas para o que eu vou usar isso?", intensificando ainda mais a ideia de que o conteúdo ensinado parecia muito distante do contexto dos alunos; a contextualização não estava presente. Para responder à pergunta, a professora apenas mencionou 
que, em uma indústria (na qual provavelmente o aluno trabalharia), o reagente limitante determina a quantidade de produtos que se formam.

Após o intervalo, a professora deu início a outro conteúdo: pureza. Dessa vez, em alguns momentos, ela contextualizou o assunto, como quando ela mencionou que o ar não é puramente oxigênio, sendo necessário levar em consideração o nitrogênio e outros gases. Noutro momento, enquanto resolvia um cálculo demonstrativo envolvendo a pirita, ela explicou qual é a aplicação desse mineral na obtenção do ácido sulfúrico. Ela contou, ainda, que antigamente acreditavam que a pirita era ouro, por se tratar de uma pedra bem amarela, sendo, por isso, conhecida como "ouro de tolo".

Nessa segunda parte da aula, após o intervalo, os alunos já se mostravam mais participativos, respondiam quando solicitados e ajudavam a professora a resolver os cálculos, sendo que a maior parte dos alunos não estava mais usando os celulares. Isso pode estar fortemente relacionado à prática da contextualização realizada, evidenciando como o seu uso no ensino de química é crucial e pode fazer muita diferença no comportamento e na aprendizagem dos alunos. Vale ressaltar que 4 alunos voltaram 30 minutos atrasados do intervalo, demonstrando falta de interesse pela aula da professora, que até o intervalo não havia contextualizado nada.

Neste sentido, pode-se entender que “[...] a ausência da contextualização no ensino de química pode ser a responsável pelo alto nível de rejeição do estudo desta ciência pelos alunos, dificultando os processos de ensino e aprendizagem" (LIMA, 2000, p. 26). Além disso, há um índice significativo quanto aos números de evasão e repetência de alunos nos cursos técnicos, muitas vezes derivados da fragilidade em que se desenvolve a prática pedagógica.

Entretanto, em especial nesta aula, é sagaz pensar que a professora apresenta dificuldades em contextualizar seus conhecimentos científicos, pois é notório a gama de saberes conteudistas que esta apresenta. Assim, revela-se, de acordo com Moraes e Bedin (2017, p. 124), “[...] a necessidade da participação do professor na gestão da disciplina. Essa participação requer muito deste profissional que, muitas vezes, não possui as ferramentas adequadas para o manejo desta questão tão complexa". Ou seja, uma formação contínua no viés de metodologias docentes seria necessária a esta profissional, pois Pires (1999 apud MORAES; BEDIN, 2017 , p. 125) afirma que o docente, às vezes por comodismo próprio, por falta de apoio da escola ou por deficiência na formação acadêmica, não se encontra pre- 
parado psicologicamente para receber os impactos inevitáveis e as problemáticas características de sua profissão.

A quarta e última aula observada foi a de Processos Industriais I (Tintas), sendo realizada no turno diurno e com duração de 4 períodos, sendo assistida por 15 alunos. Essa foi uma aula diferente, pois se tratou de uma visita técnica à empresa PPG Tintas Renner, no município de Gravataí, pertencente à região metropolitana de Porto Alegre. Por si só, a visita técnica com um viés educativo já foi uma forma de contextualizar o que havia sido trabalhado pela professora em aulas anteriores. A partir dela, a turma pôde conhecer o processo produtivo das tintas, como funciona a logística dessa indústria, bem como os laboratórios e os ensaios de qualidade a serem feitos. Afinal, a visita técnica no ensino de química, segundo Santana (2016, p. 1), “[...] é um meio de adquirir conhecimento, pois se for usado de forma objetiva possibilita ao aluno aprendizado, uma vez que amplia sua visão para uma nova leitura do mundo".

Além disso, o autor contempla que:

A visita técnica com o fim pedagógico proporciona unir o aprendizado ao lúdico. Com isso os alunos vão conhecer novos lugares, conhecer novas culturas, aceitar as diferenças do próprio grupo e do lugar visitado, ter responsabilidades, flexibilidade, lidar com possíveis situações inusitadas, divertirem-se, fatores os quais vão prepará-los para a vida adulta (SANTANA, 2016, p. 1).

Inicialmente, os alunos tiveram uma aula sobre tintas com uma instrutora da PPG, que também os levou para conhecer os processos da empresa. Tanto durante a aula quanto durante a visita ao setor de produção, os alunos mostraram muito interesse e curiosidade por tudo o que lhes era apresentado. Fizeram questionamentos e também responderam quando a professora os questionava. Assim, pode-se dizer que um evento de contextualização como esse desperta o interesse, promove a curiosidade e, consequentemente, facilita o aprendizado efetivo do aluno.

Por fim, diante das observações realizadas nas 4 turmas envolvendo o conteúdo de química, pode-se afirmar que contextualizar no ensino de química é uma ação fundamental para a participação e a interação dos alunos, tendo um impacto positivo sobre a aprendizagem, pois, analisando as turmas observadas, foi notório que, ao utilizar a contextualização como recurso, os professores conseguiram maior êxito no desenvolvimento da ensinagem, prendendo a atenção da turma com seriedade e veemência. 
Isso pode ser constatado a partir de alguns sinais demonstrados pelos alunos, como, por exemplo, o fato de nenhum deles utilizar o celular na aula da professora de Polímeros - aula extremamente contextualizada. Além disso, ainda na aula desta professora, os alunos conseguiram trazer problemas do cotidiano para o contexto da aula, o que demonstra que eles entenderam e fizeram relações com o que a professora estava ensinando.

Da mesma forma, analisando a aula do professor de Química Orgânica I, foi possível constatar que, ao usar a contextualização, os alunos mostraram maior aliciação no desenvolvimento do conteúdo. Assim, mesmo comparando a aula da professora de Polímeros com a aula do professor de Química Orgânica I, a qual não foi tão contextualizada quanto a primeira, ele conseguiu manter a atenção e o interesse da turma. Poucos alunos utilizaram os celulares, pois se preocuparam em fazer perguntas ao professor sobre o que estava sendo explanado e, ainda, responder às questões solicitadas.

Em contrapartida, a aula da professora de Química Inorgânica I foi a que menos envolveu a ação de contextualizar. Assim, pode-se concluir que a aula dela apresentou dois momentos totalmente distintos: um antes do intervalo, no qual ela não usou um contexto para explicar o conteúdo, em nenhum momento; e outro após o intervalo, quando ela fez uso, mesmo que em poucos momentos, da contextualização. No primeiro momento, a turma estava impassível, utilizando o celular e não participando da aula, de modo que a professora precisou chamar a atenção dos alunos. Já, no segundo, naquele em que houve um pouco de contextualização, a turma demonstrou maior interesse, não usou o celular, respondeu as questões e participou da aula ativamente. Logo, evidencia-se que a contextualização no ensino de química gera impactos positivos na postura e no aprendizado dos alunos, sendo notória a diferença no processo de aprendizagem com a contextualização.

Em relação à turma que fez a visita técnica, ficaram perceptíveis a curiosidade, a participação e o entusiasmo diante do processo. Na empresa, os alunos puderam ver e entender onde e como os conceitos teóricos aprendidos em aula são aplicados - houve uma conexão entre a teoria e a prática por meio da atividade docente e a retomada de conhecimentos e conceitos por meio de questionamentos e problematizações. Além disso, os estudantes puderam perceber a importância de uma tinta de qualidade para as casas, não servindo apenas para embelezar, mas, principalmente, para proteger as superfícies. Ainda, é necessário destacar que, em 
diversos momentos, a professora fez perguntas sobre tintas e suas propriedades, instigando os alunos e, em meio a competências e habilidades, demonstrando real entendimento e compreensão do conteúdo explanado.

Diante do exposto, pode-se compreender que a contextualização tem forte caráter educativo e influencia positivamente na qualificação e na maximização dos processos de ensino e aprendizagem. Afinal, de acordo com Moraes e Bedin (2017, p. 115), “[...] a escola, enquanto instituição social, é um dos espaços privilegiados de formação e informação, em que a aprendizagem dos conteúdos deveria encontrar-se em sintonia com as questões sociais e culturais do estudante".

\section{Considerações finais}

Diante do que foi observado durante as aulas na escola técnica, é possível constatar que a contextualização no ensino de química é, sim, fundamental para os processos de ensino e aprendizagem e, principalmente, para fazer com que o aluno perceba seus saberes do contexto relacionados ao conteúdo científico adquirido em sala de aula. Além disso, é notório perceber que os professores que fizeram uso desse processo obtiveram maior sucesso em sala de aula, tanto na participação quanto na compreensão, na seriedade e no comportamento dos alunos.

Com a análise dos dados coletados no decorrer da observação, ficou evidente que o ensino contextualizado promove a construção significativa dos alunos, despertando a curiosidade e o interesse pelo saber científico. A postura das turmas foi positiva diante dos assuntos que foram contextualizados, de tal forma que os estudantes não fizeram uso do celular, não se dispersaram ou atrapalharam a aula, pelo contrário: foram questionadores, interessados, souberam responder a questões referentes ao conteúdo quando solicitados e, ainda, trouxeram contribuições para a aula. De maneira oposta, os alunos se mostraram apáticos e desinteressados diante de uma aula não contextualizada.

Todavia, como destacado anteriormente, é necessário que os profissionais da educação, não especificamente aqueles que tiveram suas aulas observadas, busquem uma formação continuada à luz de metodologias significativas no ensino de química, pois muitos são os professores que desenvolvem em sala de aula exatamente aquilo que obtiveram durante a graduação, e, em especial, muitos professores de escolas 
técnicas não são licenciados, mas apresentam saberes satisfatórios em relação à disciplina que ministram.

Portanto, vale salientar que é importante que os docentes das múltiplas áreas, mas principalmente os de Química e outras ciências exatas, façam uso da contextualização durante o desenvolvimento curricular nos processos de ensino e aprendizagem, pois esta é, com certeza, uma forma de aproximar os alunos da ciência, de instigá-los e fazê-los perceber que a química está presente em seu cotidiano. Além disso, a ação de contextualizar é uma forma de demonstrar as competências e as habilidades do docente, proliferando saberes e reflexões acerca de sua formação continuada enquanto um ser comprometido e dedicado com o ato de ensinar e qualificar a aprendizagem.

\section{The contextualization and its impacts on the teaching and learning processes of chemical science}

\section{Abstract}

The practice of contextualizing in the teaching of chemistry, although being difficult to find, is a significant activity for the construction of student learning, because when carried out in a satisfactory way it has the capacity to signify its knowledge of the context in light of the maximization and acquisition of the scientific content. In this sense, the present article aims to understand how the contextualization is used in the chemistry teaching and how it can impact the posture, learning and connection of the knowledge context to the scientific contents through participation of the students in the classroom. The data were collected through observation in four different classes in Technical Education, considering the use of the Logbook and the interpretation and reflection of its content for the qualification of the data. In the end, it can be seen that contextualization qualifies the teaching process insofar as the student is a cooperative part of the construction of his scientific knowledge from its context, besides that it is a way to demonstrate the competences and abilities of the teacher, proliferating knowledge and reflections about their initial training and the necessity for continuous training with a view to teaching methodologies that value student knowledge.

Keywords: Contextualization. Teaching of Chemistry. Knowledge. 
ALVES, F. C. Diário - um contributo para o desenvolvimento profissional dos professores e estudo dos seus dilemas. Instituto Politécnico de Viseu, 2001. Disponível em: www.ipv.pt/millenium/ millenium29/30. Acesso em: 02 mar. 2019.

BRASIL. Parâmetros Curriculares do Ensino Médio (PCNEM). 2000. Disponível em: http://portal. mec.gov.br/seb/arquivos/pdf/blegais.pdf. Acesso em: 25 fev. 2019.

BRASIL. Secretaria de Educação Básica. Ministério da Educação. Orientações Curriculares para o Ensino Médio. Volume 2. Ciências da natureza, matemática e suas tecnologias. Brasília, DF: Ministério da Educação, 2006.

LIMA, J. F. L. A contextualização no ensino de cinética química. Química Nova na Escola, São Paulo, n. 11, p. 26-29, maio 2000. Disponível em: http://qnesc.sbq.org.br/online/qnesc11/v11a06. pdf. Acesso em: 08 fev. 2019.

MARCELINO-JR., C. A. C. et al. Perfumes e essências: a utilização de um vídeo na abordagem das funções orgânicas. Química Nova na Escola, São Paulo, v. 19, n. 1, p. 15-18, 2004. Disponível em: http://qnesc.sbq.org.br/online/qnesc19/a05.pdf. Acesso em: 14 mar. 2019.

MORAES, C.; BEDIN, E. Indisciplina e falta de autonomia em sala de aula: fatores que influenciam nos processos de ensino-aprendizagem. Pedagogia em Foco, Iturama, MG, v. 12, n. 8, p. 114-133, jul./dez. 2017. Disponível em: http://revista.facfama.edu.br/index.php/PedF/article/ view/314. Acesso em: 21 mar. 2019.

OLIVEIRA, A. M. C. A química no ensino médio e a contextualização: a fabricação do sabão como tema gerador de ensino aprendizagem. 2005. Dissertação (Mestrado em Ensino de Ciências Naturais e da Matemática) - Curso de Pós-Graduação em Ensino de Ciências Naturais e da Matemática, Universidade Federal do Rio Grande do Norte, Natal, 2005. Disponível em: https:// repositorio.ufrn.br/jspui/bitstream/123456789/16027/1/AnaMariaCO.pdf. Acesso em: 24 mar. 2019.

RAMOS, M. N. A contextualização no currículo de ensino médio: a necessidade da crítica na construção do saber científico. São Paulo: Mimeo, 2004.

RICARDO, E. Competências, interdisciplinaridade e contextualização: dos parâmetros curriculares nacionais a uma compreensão para o ensino das ciências. 2005. Tese (Doutorado em Educação) - Centro de Centro de Ciências Físicas e Matemáticas, Centro de Ciências da Educação, Centro de Ciências Biológicas, Universidade Federal de Santa Catarina, Florianópolis, 2005.

ROGERS, C. Tornar-se pessoa. Tradução de Ferreira, M. J. C. e Lamparelli, A. 3. ed. São Paulo: Martins Fontes, 2001.

SANTANA, E. R. Visita técnica como prática pedagógica para o ensino de química. In: ENCONTRO NACIONAL DE ENSINO DE QUÍMICA, 18, 2016. Disponível em: http://www.eneq2016. ufsc.br/anais/resumos/R0150-2.pdf. Acesso em: 07 abr. 2019.

SANTOS, A. O. Dificuldades e motivações de aprendizagem em Química de alunos do ensino médio investigadas em ações do (Pibid/UFS/Química). Scientia Plena, Sergipe, v. 9, n. 7, p. 1-6, mar. 2013. Disponível em: https://www.scientiaplena.org.br/sp/article/viewFile/1517/812. Acesso em: 24 mar. 2019.

SILVA, E. L. Visões de contextualização de professores de Química na elaboração de seus próprios materiais didáticos. Revista Ensaio, Belo Horizonte, v. 12, n. 1, p. 101-118, jan. 2010. Disponível em: http://www.scielo.br/pdf/epec/v12n1/1983-2117-epec-12-01-00101.pdf. Acesso em: 25 mar. 2019. 